\title{
Impact of heat treatment and flavorings on the antioxidant capacity of black and green tea
}

\author{
ZSANETT BODOR $^{1,2}$, BIANKA PERGEL $^{1}$ and CSILLA BENEDEK ${ }^{1 *}$
}

\footnotetext{
${ }^{1}$ Department of Dietetics and Nutrition, Faculty of Health Sciences, Semmelweis University, 17 Vas St., 1088 Budapest, Hungary

${ }^{2}$ Department of Measurement Techniques and Process Control, Szent István University, Faculty of Food Science, 14-16 Somlói St., 1118 Budapest, Hungary
}

\section{CONFERENCE FULL PAPER}

Received: August 13, 2020 • Accepted: October 4, 2020

Published online: November 18, 2020

(C) 2020 The Author(s)

\section{ABSTRACT}

Thehigh antioxidant capacity of tea is well-known, but the effect of flavorings likehoney orlemon has been less studied. Their antioxidants can interact with each other, the global result being also affected by the brewing temperature.

The combined effect of heat ( 55 and $80^{\circ} \mathrm{C}$ ) and flavorings (acacia and honeydew honeys, lemon juice) on the total polyphenol, total flavonoid content and antioxidant capacity of black and green teas was studied.

In many cases higher antioxidant capacity was obtained at $80^{\circ} \mathrm{C}$. Teas flavored with honeydew honey had higher antioxidant capacity than those containing acacia honey. Addition of lemon decreased the antioxidant capacity of tea with honey. No synergies were confirmed in any of the compositions investigated. Vitamin $\mathrm{C}$ content of lemon-containing black tea was reduced by half at $80{ }^{\circ} \mathrm{C}$ compared to tea brewed at $55^{\circ} \mathrm{C}$; while honey was shown to partly prevent this loss of ascorbic acid.

\section{KEYWORDS}

tea, heat treatment, flavoring, antioxidant, Maillard

\section{INTRODUCTION}

The use of natural antioxidants, especially those derived from plants, was found to successfully combat stress-related diseases. Tea, whether green or black, is widely known for its valuable health-

\footnotetext{
${ }^{*}$ Corresponding author. E-mail: benedek.csilla@se-etk.hu
} 
promoting effects (Annunziata et al., 2018; Gardner et al., 2007). The bioactive compounds in green teas are mainly flavan-3-ols (catechins), proanthocyanidins (tannins) and flavonols, while black tea contains theaflavins and thearubigins (Malongane et al., 2017). Lemon and honey are also rich in antioxidants (mainly polyphenols, respectively ascorbic acid in lemon) and are popular tea flavorings, used as natural home remedies, especially for preventing infective respiratory diseases. Honey is a rich source of phytochemicals, especially phenolic compounds that vary depending on the type and origin of honey. It is known that honeydew honeys, darker in color, are higher in phenolics than floral honeys, especially the lightly colored ones like acacia honey (Alvarez-Suarez et al., 2009; Kaszab et al., 2017). The properties of honeys also vary according to their exposure to heat. Heat treatment of the honey can influence its composition and physicochemical properties (Bodor et al., 2019; Božiková et al., 2018). The proper timing and temperature of addition of either lemon or honey has generated debates over generations due to the concerns related to heat damage of bioactive materials from both honey and lemon (Pereira et al., 2013).

Research dealing with the effect of brewing temperature stated that various teas brewed at room temperature had significantly higher antioxidant capacities and flavonoid contents than those prepared with hot water (Damiani et al., 2014; Lantano et al., 2015).

Antioxidant capacity of commercial lemon-flavored black teas sweetened with different types of honey was also investigated (Pereira et al., 2013). Results showed that the use of honey, especially the darker types, enhances the antioxidant activity of lemon-flavored black tea.

Effect of honey addition to green tea and herbal teas was also examined at different temperatures (Toydemir et al., 2015). The results obtained for green tea showed that polyphenol content increased continuously upon honey addition as temperature increased, especially when honeydew honey was used, while the increase was not consistent when antioxidant capacity and especially total flavonoid content were examined. The trends depended on the matrix, i.e. green or different herbal teas and different honey types. These effects were attributed by the authors to the Maillard processes taking place at higher temperatures, when brown pigments, melanoidins are formed, these having antioxidant properties.

Antioxidant properties of fruit teas were examined in combination with ascorbic acid and honey. The results are somehow intriguing, due to the fact that ascorbic acid contributed to the increase of antioxidant capacity and polyphenol content of teas, while supplementary addition of honey proved to have a detrimental effect on these parameters (approximately $20 \%$ decrease). The supposed cause of the observed phenomenon is the formation of glycosides from honey sugars and phenolic compounds as aglycons (Belščak et al., 2011).

The present work focuses on the investigation of the impact of honey and lemon added to black and green teas at different temperatures, in order to define the conditions enabling optimal antioxidant capacity, polyphenol and flavonoid levels. Possible synergistic effects are also subjects of the research presented.

\section{MATERIALS AND METHODS}

\section{Tea and honey samples}

In this study unflavored black (FT) and green (ZT) teas were purchased from retail commerce, while acacia (A) and honeydew (E) honeys were obtained from domestic beekeepers. Lemon (C) was bought in regular supermarket, then its juice was squeezed, filtered and stored at $-18{ }^{\circ} \mathrm{C}$. 


\section{Methods}

Preparation of tea brews. Teas (green tea - ZT, black tea - FT) were brewed for 3 minutes using boiling distilled water ( $1 \mathrm{~g}$ tea for $100 \mathrm{~mL}$ water). The usually used amounts of honey $(5 \mathrm{~g}, \mathrm{~A}-$ acacia or $\mathrm{E}$ - honeydew) and/or lemon juice $(5 \mathrm{~mL}, \mathrm{C})$ were added to the cooling teas at two different temperatures: 80 or $55{ }^{\circ} \mathrm{C}$. Unflavored control teas were brewed at $80{ }^{\circ} \mathrm{C}$. Two brews were prepared and flavored for each type of tea (green/black). The prepared tea samples were stored at $-18{ }^{\circ} \mathrm{C}$ until the analytical measurements.

\section{Total polyphenol content and antioxidant capacity assays}

Sample preparation (stock solution). One milliliter of tea sample was diluted 10 times with distilled water and this stock solution was used for the measurements. All the spectrophotometric measurements were performed in five replicates per sample on a Thermo Helios Alpha UV-VIS spectrophotometer $( \pm 0.001 \mathrm{au})$, using cells of $1 \mathrm{~cm}$ path.

CUPRAC - Cupric Reducing Antioxidant Capacity assay. The reduction power of teas against copper (II) ion was estimated according to the procedure described by Apak et al. (2007). To $1 \mathrm{~mL} 10^{-2} \mathrm{M} \mathrm{CuCl}_{2}$ solution $1 \mathrm{~mL}$ of $1 \mathrm{M}$ ammonium acetate buffer $(\mathrm{pH}=7), 1 \mathrm{~mL}$ of $7.5^{\star} 10^{-3} \mathrm{M}$ neocuproine solution and $0.2 \mathrm{~mL}$ of tea stock solution were added, completed by 0.9 $\mathrm{mL}$ distilled water. Measurements were performed after a 30-min incubation period in the dark at $450 \mathrm{~nm}$, against a blank. Trolox was used as calibration standard (125-1,250 mmol trolox acid/100 mL, 5 concentrations), results were reported as mmol trolox equivalents per $1 \mathrm{~L}$ tea (mg TE/1 L tea).

Total polyphenol content. Total polyphenol content (TPC) was determined by the FolinCiocalteu method, following a procedure adapted from Singleton and Rossi (1965). $1 \mathrm{~mL}$ of the stock solution solution was put in a test tube, and $7.5 \mathrm{~mL}$ distilled water was added, followed by $0.5 \mathrm{~mL}$ of Folin-Ciocalteu reagent. After 3 minutes $1 \mathrm{~mL}$ saturated $\mathrm{Na}_{2} \mathrm{CO}_{3}$ solution was added. Absorbances were read at $750 \mathrm{~nm}$ against a blank, after a 30 -min incubation period in the dark. Gallic acid was used as calibration standard (0-100 mg gallic acid/100 mL, 5 concentrations), results were expressed as mg equivalents of gallic acid per $1 \mathrm{~L}$ tea (mg GAE/1 L tea).

Total flavonoid content. Total flavonoid content was measured by the $\mathrm{AlCl}_{3}$ method (Zhishen et al., 1999): to $1 \mathrm{~mL}$ of tea sample diluted at 1:4, $1 \mathrm{~mL}$ water and $0.3 \mathrm{~mL} 5 \% \mathrm{NaNO}_{2}$ were added. After 5 minutes $0.3 \mathrm{~mL} 10 \% \mathrm{AlCl}_{3}$ was added. After 5 minutes of waiting $2 \mathrm{~mL} 1 \mathrm{M}$ $\mathrm{NaOH}$ was added, then the total volume was brought to $10 \mathrm{~mL}$ with water. Measurements were performed at $415 \mathrm{~nm}$ against a blank, using catechin as calibrating standard (0-100 mg catechin/ $100 \mathrm{~mL}, 5$ concentrations). Results were expressed as mg equivalents of catechin per $1 \mathrm{~L}$ tea (mg $\mathrm{CE} / 1 \mathrm{~L}$ tea).

Ascorbic acid content. Ascorbic acid was quantified in some of the samples using an enzymatic kit procured from Megazyme (Ascorbic Acid Assay Kit (L-Ascorbate), K-ASCO). Measurements were performed in 4 replicates. 
Statistical analysis. Statistical analysis of the results has been performed using descriptive statistics in Excel. Mean and standard deviation was calculated from the obtained repetitive measurements per sample type. The significant effect of temperature and added flavorings (group) and their interaction (temperature ${ }^{\star}$ group) were analyzed using two-way MANOVA in SPSS 25 (IBM SPSS software). One-way ANOVA test was used to compare the flavored samples to control. The two different types of tea were evaluated separately during the MANOVA or ANOVA test. Normality of the variables was tested with Shapiro-Wilk test. Levene-test was used for checking the homogeneity of the variances. Due to the fact the homogeneity of variances was not assumed, Welch test was applied for pairwise comparison for temperature values, while Games-Howell test was applied for group comparison (Tabachnick and Fidell, 2013).

Standard deviations and significant differences between groups and temperatures are given in the figures (Figs. 1-3) for the different measurements. Asterisks indicate the significant differences between flavored samples and control, unflavored teas, based on the results of the one-way ANOVA test. Lowercase letters indicate in each case statistically significant differences between groups (groups denote flavorings, such as ZTE, ZTA, ZTAC, ZTEC, FTE, FTA, FTEC, FTAC). Capital letters indicate the differences between values obtained for the two temperature levels (55 and $80{ }^{\circ} \mathrm{C}$ ) at the same tea type within groups (i.e. flavorings, as indicated above).

\section{RESULTS AND DISCUSSION}

\section{In vitro antioxidant capacity (CUPRAC assay)}

In the case of green teas (Fig. 1) no significant differences were found for teas flavored with acacia honey and lemon prepared at $55^{\circ} \mathrm{C}\left(\right.$ ZTAC_55) or $80^{\circ} \mathrm{C}($ ZTAC_80). Moreover, antioxidant capacities were significantly higher at $80^{\circ} \mathrm{C}$ in the case of teas prepared with only lemon (ZTC) or

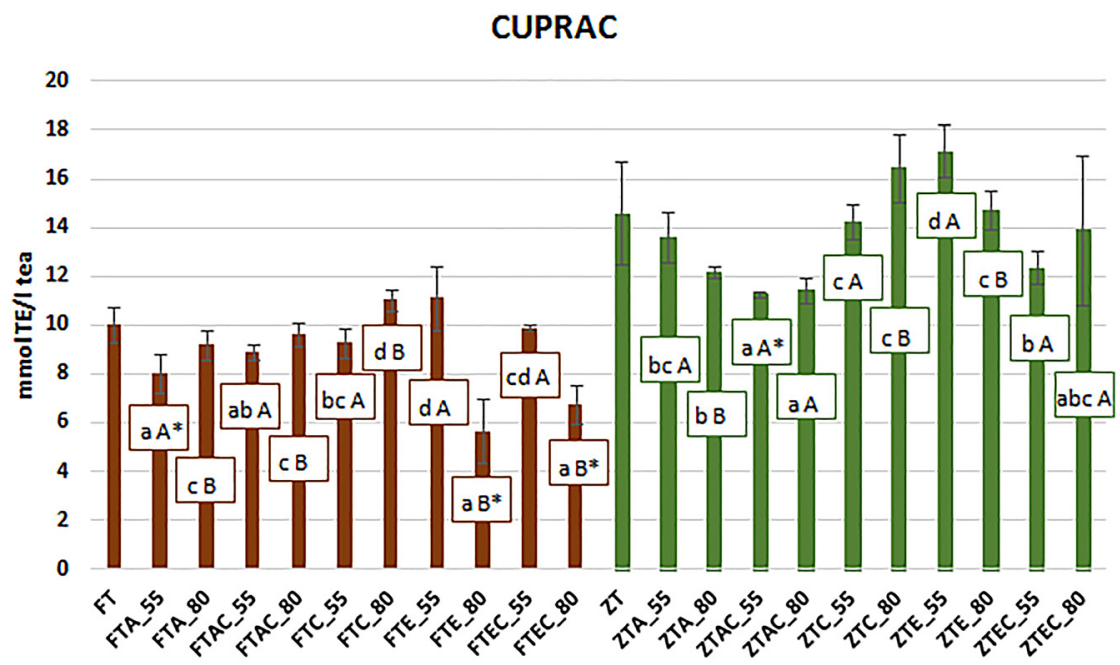

Fig. 1. Mean \pm standard deviation of CUPRAC antioxidant capacity of tea samples. *: significantly different from control tea; lowercase letters: comparison of groups at the same temperature (Games-Howell test $P<0.05$ ); capital letters: comparison of temperature levels at the same tea type within groups (Welch-test $P<0.05$ ) 


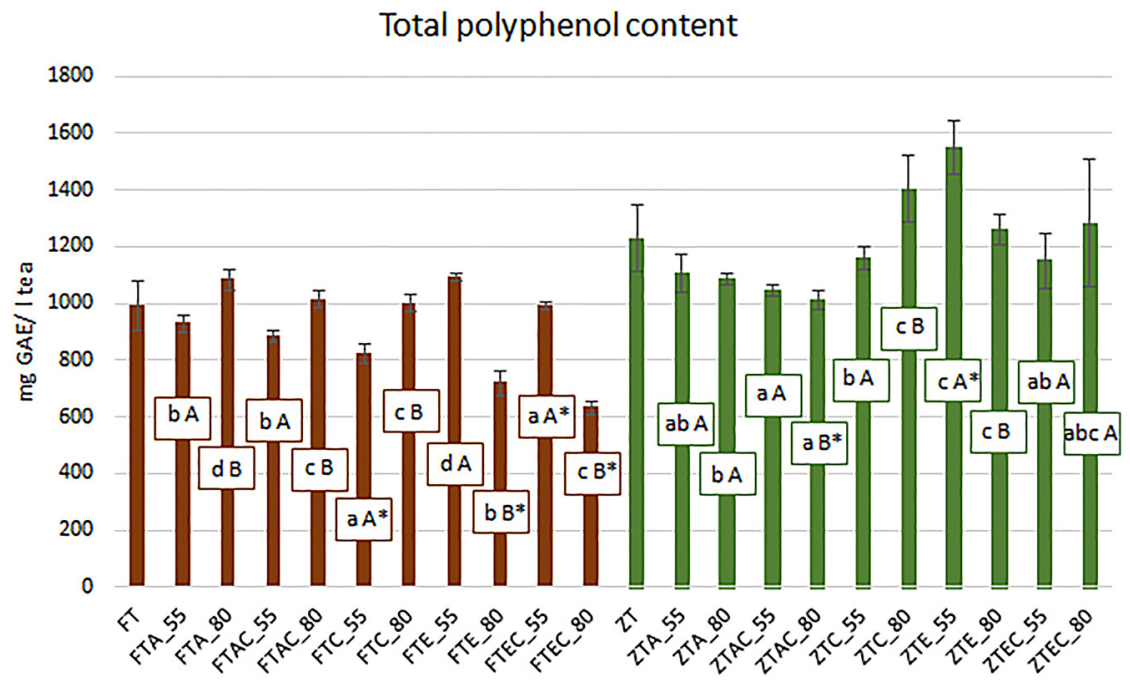

Fig. 2. Mean \pm standard deviation of total polyphenol content of tea samples *: significantly different from control tea; lowercase letters: comparison of groups at the same temperature (Games-Howell test $P<0.05$ ); capital letters: comparison of temperature levels at the same tea type within groups (Welch-test $P<0.05$ )

honeydew honey and lemon (ZTEC), respectively acacia honey and lemon (ZTAC). Teas containing honeydew honey (ZTE) have higher overall antioxidant capacities compared to those flavored with acacia honey (ZTA). Teas containing both honey and lemon reached generally lower values than those containing only one of these ingredients, when the same temperatures are compared. Thus, no synergistic effects in relation to green tea, honey or lemon were observed. One flavored tea (ZTAC_55) showed significantly lower performance than pure green tea.

Similarly to green teas, black teas (FT) did not show the expected clear decrease of antioxidant capacity with temperature. The highest values were obtained for teas prepared with only lemon (FTC_80) or only honeydew honey (FTE_55). Some of the flavored teas (FTA_55, FTE_80, FTEC_80) had significantly lower antioxidant capacities than the original black tea.

As regards the possible explanations for the inconsistent antioxidant values obtained for honey- and lemon-containing teas, two effects should be taken into account: on the one hand, the formation of melanoidins occurs in Maillard process - these molecules are known to show a high antioxidant activity. The production of Maillard reaction was reported already at temperatures as low as $70{ }^{\circ} \mathrm{C}$ (Toydemir et al., 2015). On the other hand, heat damage and consumption of both ascorbic acid and polyphenols as reactants in the Maillard reaction take place as counter processes (Nayak et al., 2015).

Finally, the effect exerted by honey on green and black teas may also be partly explained by the effect of sugars on the extraction of polyphenols from tea (Shalaby et al., 2016).

\section{Total polyphenol content (TPC, Folin-Ciocalteu assay)}

Similarly to CUPRAC results, teas prepared with honeydew honey showed better performance than those containing acacia honey, this is due to the higher phenolic compound content of 


\section{Total flavonoid content}

300

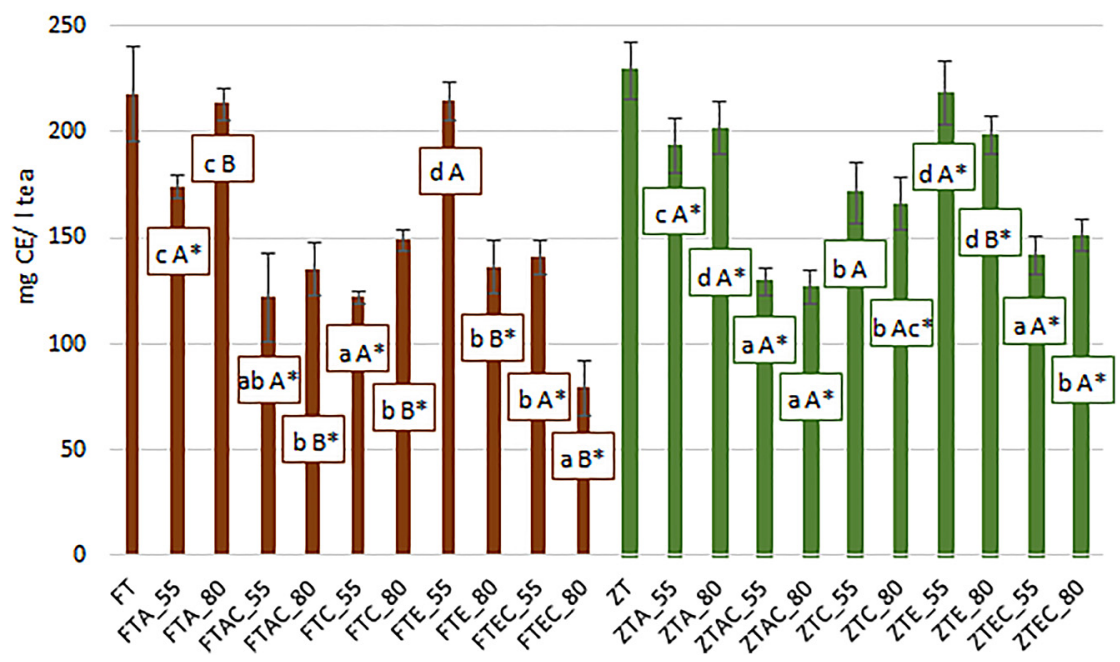

Fig. 3. Mean \pm standard deviation of total flavonoid content of tea samples. *: significantly different from control tea; lowercase letters: comparison of groups at the same temperature (Games-Howell test $P<0.05$ ); capital letters: comparison of temperature levels at the same tea type within groups (Welch-test $P<0.05$ )

honeydew honey (Fig. 2). Temperature difference affects polyphenol content in most of the cases, but in many cases higher temperatures led to higher polyphenol contents (e.g. FTA, FTAC, ZTC). This can be due to the melanoidins produced in the Maillard process that can react with the Folin-Ciocalteau reagent, contributing thus to the measured total polyphenol content (Toydemir et al., 2015). This may explain the higher polyphenol content values in our honey-containing tea samples at higher temperatures of honey addition. On the other hand, phenolic compound content in teas containing only lemon or only honey is either higher or does not differ significantly from those containing both ingredients, thus no synergistic effects were evidenced at any of the brewing temperatures. The lower values measured for teas prepared with both honey and lemon are attributed to the formation of glycosides between the -OH moieties of phenols and sugars in honey, as described in the literature by authors who obtained similar decrease for honey-containing fruit teas (Belščak et al., 2011).

Use of honeydew honey resulted in higher polyphenol content in black teas compared to those containing acacia honey at $55{ }^{\circ} \mathrm{C}$. The addition of lemon led to polyphenol contents significantly lower than in the case of original tea, this is due to the lower polyphenol content of lemon.

Total flavonoid content (TF, $\mathbf{A l C l}_{3}$ assay). Excepting green tea with honeydew honey, no significant flavonoid losses were confirmed for green teas flavored with the same ingredients at lower or higher temperature (Fig. 3), so no significant flavonoid losses are confirmed at these temperatures. Unlike for CUPRAC antioxidant capacity and Folin assay, here Maillard reaction 
products do not contribute to the global flavonoid content, thus values obtained at $80{ }^{\circ} \mathrm{C}$ were not superior to those measured for teas flavored at $55{ }^{\circ} \mathrm{C}$. Instead of synergies between honey and lemon, a constant decrease was observed for teas with honey and lemon compared to those containing only honey or lemon. The well-known high flavonoid content of green tea was confirmed in comparison to any flavored tea containing either lemon or honey, however, the higher flavonoid content of honeydew honey (Lachman et al., 2010) was confirmed in our flavored tea samples.

The flavonoid content pattern for black teas was different from the one obtained for green teas. Except for the teas flavored with honeydew honey, all the teas show higher flavonoid content at $80^{\circ} \mathrm{C}$ compared to their pairs prepared at $55^{\circ} \mathrm{C}$, this suggesting that some compounds are formed that contribute to the overall flavonoid content result. Teas containing both lemon and honey show lower values than those containing only one of these ingredients. The high flavonoid content of pure black tea is equaled only by the teas containing acacia or honeydew honey.

Ascorbic acid content. Ascorbic acid was determined for the black tea samples containing lemon. A decrease of the original ascorbic acid content of lemon juice by $50 \%$ was observed for all the sample pairs investigated when teas prepared at 55 and $80{ }^{\circ} \mathrm{C}$ were compared. For teas containing only lemon, but not honey, much lower values were obtained (FTC_55: 8.10 \pm 0.67 $\mathrm{mg} / \mathrm{L}$ vs. FTC_80: $3.81 \pm 0.01 \mathrm{mg} / \mathrm{L}$ ) than for either acacia honey-lemon (FTAC_55: $27.27 \pm$ $2.25 \mathrm{mg} / \mathrm{L}$ vs. FTAC_80: $12.73 \pm 1.50 \mathrm{mg} / \mathrm{L}$ ) or honeydew honey-lemon (FTEC_55: $23.18 \pm 8.36$ $\mathrm{mg} / \mathrm{L}$ vs. FTEC_80: $10.91 \pm 1.29 \mathrm{mg} / \mathrm{L}$ ) teas. For both flavored tea types (only lemon and lemonhoney) the same degree of decrease was observed, i.e. almost half of the ascorbic acid was lost. However, honey-containing teas (FTAC and FTEC) showed much higher ascorbic acid contents compared to tea containing only lemon (FTC), which can be explained by the native ascorbic acid content of honey, which is around $0.9 \mathrm{mg} / \mathrm{g}$ for both honeys used (Dobrinas et al., 2006). If the original honey amount $(5 \mathrm{~g})$ in our teas is taken into account, this would correspond to a theoretic content of approximately $40-45 \mathrm{mg}$ ascorbic acid per liter of honey-containing tea if any heat damage would be excluded. On the other hand, the higher amounts of preserved ascorbic acid in teas with added honey can also be due to the reported protective effects of phenolic antioxidants against the oxidative decomposition of ascorbic acid (Miller and RiceEvans, 1997). Thus, the use of honey potentiates significantly the ascorbic acid content of tea, which is, among other phytochemicals - i.e. mainly polyphenols - an additional advantage of the use of honey as a sweetener.

\section{CONCLUSION}

The comparison on the effect of honey or lemon addition to green and black tea samples at different temperatures revealed that the total polyphenol, flavonoid content and CUPRAC antioxidant capacity of the honey-added tea samples were generally lower than those of the control tea samples. Combination of lemon and honey led to lower antioxidant, polyphenol and flavonoid values in many cases compared to either pure tea or teas containing only lemon or only honey. Temperature increase did not result in a consistent trend in the change of the parameters investigated. These effects were mainly attributed to parallel processes with counter effects: on the one hand, the contribution of antioxidant Maillard reaction products and on the other hand, consumption of ascorbic acid and polyphenols under heat effect and Maillard 
reaction, and additional formation of polyphenol glycosides. Unlike for antioxidant properties, the temperature increase had a clear negative impact on the ascorbic acid content, which dropped to half of the initial value in the black tea samples investigated. Ascorbic acid content was much higher in black teas containing honey and lemon than in those containing only lemon, this is due partly to the native ascorbic acid content of honey and may be partly explained by the protective effects of phenolic antioxidants present in honey.

Our findings do not support any synergistic effects between antioxidant properties of tea, lemon and honey in terms of global in vitro antioxidant capacity and phenolic antioxidants, however, a protective effect of these latter on the ascorbic acid content of lemon and honey was observed.

\section{ACKNOWLEDGEMENTS}

Supported by the ÚNKP-19-3-I-SZIE-71 New National Excellence Program of the Ministry for Innovation and Technology. This paper was supported by the Doctoral School of Food Science, Szent István University. The Project is supported by the European Union and co-financed by the European Social Fund (grant agreement no. EFOP-3.6.3-VEKOP-16-2017-00005).

\section{REFERENCES}

Alvarez-Suarez, J., Tulipani, S., Romandini, S., Vidal, A., and Battino, M. (2009). Methodological aspects about determination of phenolic compounds and in vitro evaluation of antioxidant capacity in the honey: a review. Current Analytical Chemistry, 5(4): 293-302, https://doi.org/10.2174/157341109789077768.

Annunziata, G., Maisto, M., Schisano, C., Ciampaglia, R., Daliu, P., Narciso, V., Tenore, G.C., and Novellino, E (2018). Colon bioaccessibility and antioxidant activity of white, green and black tea polyphenols extract after in vitro simulated gastrointestinal digestion. Nutrients, 10(11), https://doi.org/10. 3390/nu10111711.

Apak, R., Güçlü, K., Demirata, B., Özyürek, M., Çelik, S.E., Bektaşoglu, B., Berker, K.I., and Özyurt, D. (2007). Comparative evaluation of various total antioxidant capacity assays applied to phenolic compounds with the CUPRAC assay. Molecules, 12(7): 1496-1547, https://doi.org/10.3390/12071496.

Belščak, A., Bukovac, N., and Piljac-Žegarac, J. (2011). The influence of ascorbic acid and honey addition on the anti-oxidant properties of fruit tea infusions: antioxidants in fruit tea infusions. Journal of Food Biochemistry, 35(1): 195-212, https://doi.org/10.1111/j.1745-4514.2010.00375.x.

Bodor, Z., Ghdir, C., Zinia Zaukuu, J.-L., Benedek, C., and Kovacs, Z. (2019). Detection of heat treatment of honey with near infrared spectroscopy. Hungarian Agricultural Engineering, 36: 57-62, https://doi.org/ 10.17676/HAE.2019.36.57.

Božiková, M., Hlaváč, P., Vozárová, V., Hlaváčová, Z., Kubík, L., Kotoulek, P., and Brindza, J. (2018). Thermal properties of selected bee products. Progress in Agricultural Engineering Sciences, 14(s1): $37-$ 44, https://doi.org/10.1556/446.14.2018.S1.4.

Damiani, E., Bacchetti, T., Padella, L., Tiano, L., and Carloni, P. (2014). Antioxidant activity of different white teas: comparison of hot and cold tea infusions. Journal of Food Composition and Analysis, 33(1): 59-66, https://doi.org/10.1016/J.JFCA.2013.09.010. 
Dobrinas, S., Matei, N., and Soceanu, A. (2006). Estimation of vitamin $\mathrm{C}$ and $\mathrm{Cd}, \mathrm{Cu}, \mathrm{Pb}$ content in honey and propolis. Scientific Study and Research, VII(1): 729-734.

Gardner, E.J., Ruxton, C.H.S., and Leeds, A.R. (2007). Black tea - helpful or harmful? A review of the evidence. European Journal of Clinical Nutrition, 61(1): 3-18, https://doi.org/10.1038/sj.ejcn.1602489.

Kaszab, T., Bodor, Z., Kovacs, Z., and Benedek, C. (2017). Classification models of Hungarian honey samples based on analytical and physical characteristics. Hungarian Agricultural Engineering, 32(32): 22-28, https://doi.org/10.17676/HAE.2017.32.22.

Lachman, J., Orsák, M., Hejtmánková, A., and Kovářová, E. (2010). Evaluation of antioxidant activity and total phenolics of selected Czech honeys. LWT - Food Science and Technology, 43(1): 52-58, https://doi. org/10.1016/J.LWT.2009.06.008.

Lantano, C., Rinaldi, M., Cavazza, A., Barbanti, D., and Corradini, C. (2015). Effects of alternative steeping methods on composition, antioxidant property and colour of green, black and oolong tea infusions. Journal of Food Science and Technology, 52(12): 8276-8283, https://doi.org/10.1007/s13197-015-1971-4.

Malongane, F., McGaw, L.J., and Mudau, F.N. (2017). The synergistic potential of various teas, herbs and therapeutic drugs in Health improvement: a review. Journal of the Science of Food and Agriculture, 97(14): 4679-4689, https://doi.org/10.1002/jsfa.8472.

Miller, N.J. and Rice-Evans, C.A. (1997). The relative contributions of ascorbic acid and phenolic antioxidants to the total antioxidant activity of orange and apple fruit juices and blackcurrant drink. Food Chemistry, 60(3): 331-337, https://doi.org/10.1016/S0308-8146(96)00339-1.

Nayak, B., Liu, R.H., and Tang, J. (2015). Effect of processing on phenolic antioxidants of fruits, vegetables, and grains-a review. Critical Reviews in Food Science and Nutrition, 55(7): 887-919, https://doi.org/10. 1080/10408398.2011.654142.

Pereira, C., Barros, L., Vilas-Boas, M., and Ferreira, I.C.F.R. (2013). Potentiating effects of honey on antioxidant properties of lemon-flavoured black tea. International Journal of Food Sciences and Nutrition, 64(2): 230-234, https://doi.org/10.3109/09637486.2012.713916.

Shalaby, E.A., Mahmoud, G.I., and Shanab, S.M.M. (2016). Suggested mechanism for the effect of sweeteners on radical scavenging activity of phenolic compounds in black and green tea. Frontiers in Life Science, 9(4): 241-251, https://doi.org/10.1080/21553769.2016.1233909.

Singleton, V.L., and Rossi, J.A. (1965). Colorimetry of total phenolics with phosphomolybdic-phosphotungstic acid reagents. Am J Enol Vitic, 16: 144-158.

Tabachnick, B.G. and Fidell, L.S. (2013). Using multivariate statistics, 6th ed. Pearson Education, Harlow, Essex.

Toydemir, G., Capanoglu, E., Kamiloglu, S., Firatligil-Durmus, E., Sunay, A.E., Samanci, T., and Boyacioglu, D. (2015). Effects of honey addition on antioxidative properties of different herbal teas. Polish Journal of Food and Nutrition Sciences, 65(2): 127-135, https://doi.org/10.1515/pjfns-2015-0019.

Zhishen, J., Mengcheng, T., and Jianming, W. (1999). The determination of flavonoid contents in mulberry and their scavenging effects on superoxide radicals. Food Chemistry, 64(4): 555-559.

Open Access. This is an open-access article distributed under the terms of the Creative Commons Attribution 4.0 International License (https://creativecommons.org/licenses/by/4.0/), which permits unrestricted use, distribution, and reproduction in any medium, provided the original author and source are credited, a link to the CC License is provided, and changes - if any - are indicated. (SID_1) 